\title{
Modeling of Lightning Strokes Using Two-Peaked Channel-Base Currents
}

\author{
V. Javor \\ Faculty of Electronic Engineering, University of Nis, Aleksandra Medvedeva 14, 18000 Nis, Serbia \\ Correspondence should be addressed to V. Javor, vesna.javor@elfak.ni.ac.rs
}

Received 15 September 2011; Revised 6 January 2012; Accepted 8 February 2012

Academic Editor: Andres Peratta

Copyright () 2012 V. Javor. This is an open access article distributed under the Creative Commons Attribution License, which permits unrestricted use, distribution, and reproduction in any medium, provided the original work is properly cited.

Lightning electromagnetic field is obtained by using "engineering" models of lightning return strokes and new channel-base current functions and the results are presented in this paper. Experimentally measured channel-base currents are approximated not only with functions having two-peaked waveshapes but also with the one-peaked function so as usually used in the literature. These functions are simple to be applied in any "engineering" or electromagnetic model as well. For the three "engineering" models: transmission line model (without the peak current decay), transmission line model with linear decay, and transmission line model with exponential decay with height, the comparison of electric and magnetic field components at different distances from the lightning channel-base is presented in the case of a perfectly conducting ground. Different heights of lightning channels are also considered. These results enable analysis of advantages/shortages of the used return stroke models according to the electromagnetic field features to be achieved, as obtained by measurements.

\section{Introduction}

One of the key issues in research of environmental electromagnetic interference with electric systems, electronic devices and equipment inside imperfectly enclosed structures, so as with power and communication lines, is modeling of lightning discharges. An adequate EMC simulation would include wide variety of modeling parameters such as various initial and boundary conditions, excitation types, ground electrical properties and different configurations of the observed systems. Rapid advance in EMC modeling and computation due to development of numerical procedures programs and computers in last few decades partly replaced expensive and cumbersome building and testing of appropriate prototypes, so as some experimental procedures. Although measurements are nowadays carried out for triggered lightning and at instrumented tall towers throughout the world, the most referred and comprehensive measurement results for natural lightning are given in [1-3].

According to [4] lightning stroke models are classified into physical (gas-dynamic) models, electromagnetic models, "engineering" models, and distributed-circuit theory models. Models based on the full-wave approach take into account radiation effects for the treatment of electromagnetic wave propagation problems. "Engineering" models use simplified approach with respect to the current distribution along the lightning channel, but electromagnetic field is determined based on the same relations as for electromagnetic models. In fact, all these models enable approximate analysis of lightning electromagnetic field and its coupling to systems or devices, due to a wide variety of conditions accompanying this natural phenomenon. There are various classifications of models given in the literature, for example $[4,5]$, and, besides, a certain model can belong to more than one class.

Many researchers are focused on comparison of different "engineering" models using the same channel-base current, but the influence of an implied current waveshape itself on lightning electric and magnetic field components is not investigated, as to the author's best knowledge. Both the selected model and channel-base current waveshape determine lightning electric and magnetic field results to be compared with experimentally obtained waveshapes at different distances from the channel base. Compliance 
with some measurements results, as, for example [1-3], is important for the validation of models.

If the new two-peaked channel-base current function [6] is used, it is possible to obtain some of the features that a certain model would not give with the one-peaked current waveshape as in $[7,8]$ or with the one-peaked current as usually used in the literature [9, 10], and so forth. If using [10] at least two terms are needed to obtain theoretically assumed current [11] having one initial and a subsidiary peak [12]. However, for experimentally measured currents as at Monte San Salvatore [1, 3] seven terms are needed in the linear combination of Heidler's functions, as gevin in [13]. This was used for calculations of lightning induced overvoltages at power transmission lines in [14]. The same number of terms was used in [13] for approximating experimentally measured currents at the Morro do Cachimbo station [15]. The adequate parameters of the new two-peaked channel-base current function are given in this paper for these two, and also for the one-peaked function [7] approximating the first negative stroke channelbase current [9].

A function having similar mathematical expression to given in [6] can be used to include even more peaks in the current waveshape. It is demonstrated that such obtained lightning electric and magnetic fields results at different distances perform some features of experimental results. A review of new functions is given in [16] for representing IEC 62305 standard currents [17] and other typical lightning stroke currents. These functions are suitable for use in both "engineering" and antenna theory models [18] to approximate the excitation at the channel base.

\section{First Negative Stroke Channel-Base Currents}

A negative first-stroke channel-base current is characterized with emphasized peaks (an initial and a few subsidiary peaks). The function including two peaks in the rising part can be approximated with the following analytical expression [6]:

$$
i(0, t)=\left\{\begin{array}{c}
I_{m 1} \sum_{i=1}^{k} d_{i}\left[\left(\frac{t}{t_{m 1}}\right) \exp \left(1-\frac{t}{t_{m 1}}\right)\right]^{a_{i}}, \\
0 \leq t \leq t_{m 1}, \\
I_{m 1}+I_{m 2} \sum_{i=1}^{l} f_{i}\left[\frac{t-t_{m 1}}{t_{m 2}-t_{m 1}} \exp \left(1-\frac{t-t_{m 1}}{t_{m 2}-t_{m 1}}\right)\right]^{b_{i}}, \\
t_{m 1} \leq t \leq t_{m 2}, \\
\left(I_{m 1}+I_{m 2}\right) \sum_{i=1}^{n} g_{i}\left[\left(\frac{t}{t_{m 2}}\right) \exp \left(1-\frac{t}{t_{m 2}}\right)\right]^{c_{i}}, \\
t_{m 2} \leq t<\infty .
\end{array}\right.
$$

The number of terms $k, l$, and $n$ is selected according to the desired accuracy of approximation. Parameters of the current function are $a_{i}, b_{i}, c_{i}$, and the weighting coefficients are $d_{i}, f_{i}, g_{i}$, so that $\sum_{1}^{k} d_{i}=\sum_{1}^{l} f_{i}=\sum_{1}^{n} g_{i}=1$. The initial peak $I_{m 1}$ is obtained at $t_{m 1}$, and the subsidiary peak $I_{m}=I_{m 1}+I_{m 2}$ at $t_{m 2}$ (Figure 1). For the analytical expression (1) parameters

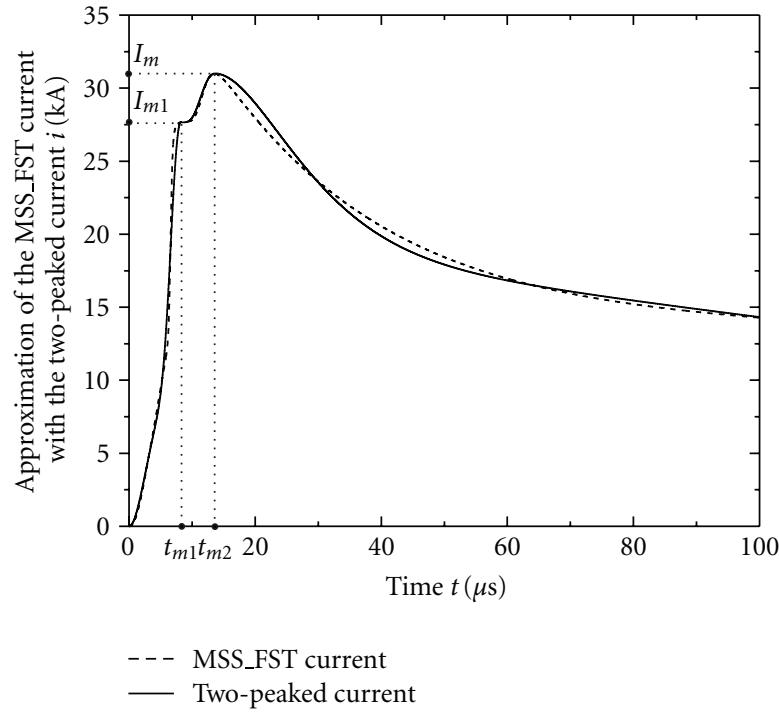

Figure 1: Two-peaked channel-base current function (full line) approximating the measurements results from [3] with the adequate function from [13] (dashed line).

TABLE 1: Two-peaked current function parameters to approximate channel-base currents MSS_FST [3] and MCS_FST [15].

\begin{tabular}{lcc}
\hline Two-peaked current parameters & MSS_FST & MCS_FST \\
\hline$I_{m 1}(\mathrm{kA})$ & 27.66 & 40.07 \\
$I_{m 2}(\mathrm{kA})$ & 3.34 & 5.215 \\
$t_{m 1}(\mu \mathrm{s})$ & 8.2 & 8.2 \\
$t_{m 2}(\mu \mathrm{s})$ & 13.6 & 13.8 \\
$d_{1}$ & 0.37 & 0.37 \\
$d_{2}=1-d_{1}$ & 0.63 & 0.63 \\
$a_{1}$ & 2.2 & 2.2 \\
$a_{2}$ & 28 & 28 \\
$f_{1}$ & 1 & 1 \\
$b_{1}$ & 5.5 & 15 \\
$g_{1}$ & 0.4 & 0.45 \\
$g_{2}=1-g_{1}$ & 0.6 & 0.55 \\
$c_{1}$ & 2 & 3.3 \\
$c_{2}$ & 0.06 & 0.055 \\
\hline
\end{tabular}

to represent median characteristics of channel-base currents measured at Monte San Salvatore [3] and at the Morro do Cachimbo station [15] are given in Table 1.

In order to compare the results of calculations to results from the literature, parameters of the one-peaked NCBC current function are calculated to represent channel-base current from [9], as used in [4] and a number of papers.

NCBC function $[7,8]$ is given with

$$
i(0, t)= \begin{cases}I_{m}\left(\frac{t}{t_{m}}\right)^{a} \exp \left[a\left(1-\frac{t}{t_{m}}\right)\right], & 0 \leq t \leq t_{m} \\ I_{m} \sum_{i=1}^{n} c_{i}\left(\frac{t}{t_{m}}\right)^{b_{i}} \exp \left[b_{i}\left(1-\frac{t}{t_{m}}\right)\right], & t_{m} \leq t \leq \infty\end{cases}
$$




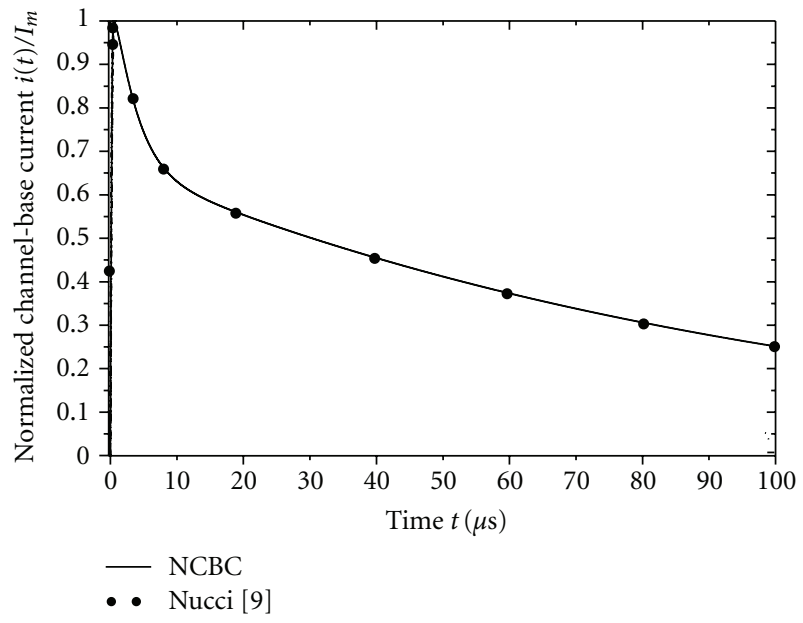

FIGURE 2: One-peaked NCBC function denoted with the full line approximating channel-base current from [9] denoted with dots.

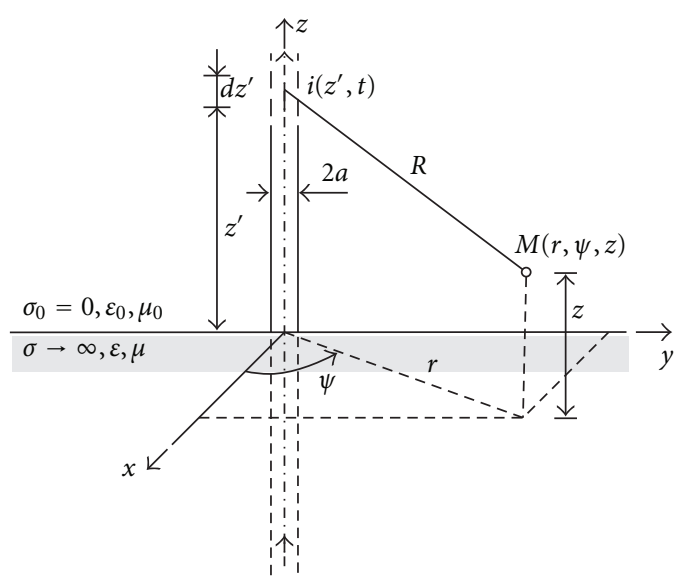

FIGURE 3: Model of a lightning channel at the perfectly conducting ground.

for $a$ and $b_{i}$ parameters, and $c_{i}$ weighting coefficients, so that $\sum_{1}^{n} c_{i}=1$. Time $t_{m}$ is the rise time to the maximum current value $I_{m}$, for the chosen number of terms $n$ in the decaying part.

NCBC function (2) approximates the waveshape from [9] presented with dots in Figure 2. Parameters for NCBC function, presented with the full line in Figure 2, are calculated as the following: $I_{m}=11 \mathrm{kA}, t_{m}=0.472 \mu \mathrm{s}$, $a=1.1, b_{1}=0.16, c_{1}=0.34, b_{2}=0.0047$, and $c_{2}=$ $1-c_{1}=0.66$ [7]. The waveshape from [9] is often used in the literature for lightning negative strokes modeling.

\section{3. "Engineering” Models of Lightning Strokes}

Thin wire representation of a lightning channel at the perfectly conducting ground is presented in Figure 3. An "engineering" model assumes an impulse current, propagating along the channel with a current-wave propagation speed $v_{f}$ and the speed $v$ of the return stroke, presented with

$$
i\left(z^{\prime}, t\right)=u\left(t-\frac{z^{\prime}}{v_{f}}\right) P\left(z^{\prime}, t\right) i\left(0, t-\frac{z^{\prime}}{v}\right),
$$

where $u(t)$ is the Heaviside function and $P\left(z^{\prime}, t\right)$ the heightand time-dependent current attenuation factor. In the transmission line (TL) model this factor is $P\left(z^{\prime}, t\right)=1$, so the current is propagating along the channel without attenuation. In the transmission line model with linear decay (MTLL), for the height $z^{\prime}$ of the observed current element above the ground, the attenuation factor is $P\left(z^{\prime}, t\right)=1-z^{\prime} / H$ for the assumed channel height $H$. In this paper $H$ is chosen to be $2600 \mathrm{~m}$ or $7500 \mathrm{~m}$. In the transmission line model with exponential decay (MTLE) is $P\left(z^{\prime}, t\right)=\exp \left(-z^{\prime} / \lambda\right)$, for the decay constant $\lambda=2000 \mathrm{~m}$ chosen in [9], so as in this paper. For all the three models $v=v_{f}=1.3 \cdot 10^{8} \mathrm{~ms}^{-1}$, as in [4], is taken for obtaining results in this paper.

The current $i(0, t)$ in (3) is the channel-base current to be approximated with one- or two-peaked pulse functions, as presented in Figures 1 and 2. All the results for vertical electric and azimuthal magnetic field are presented for points at the ground surface. There are no other electric or magnetic field components at the ground surface due to $\sigma \rightarrow \infty$ for the lower half-space (Figure 3). Above the ground other electromagnetic field components exist, but measurements results are usually given for the points very near to the ground surface.

For MTLL model the current at the end of the channel (for $z^{\prime}=H$ ) is equal to zero. The consequence is that the interrupt of the channel does not produce a spike in the waveshapes of far electric and magnetic fields. For MTLE model, the degree of attenuation depends on the value of constant $\lambda$. The higher the value of $\lambda$, the less the current is attenuated, and vice versa.

\section{Results for Lightning Electromagnetic Field}

In the upper half-space electric field has both vertical and radial component, and magnetic field just azimuthal component, whereas other field components are equal to zero in the case of perfectly conducting ground. Vertical electric field at the field point $M(r, \psi, z)$, as in Figure 3, can be calculated as

$$
\begin{gathered}
E_{z}=\frac{1}{4 \pi \varepsilon_{0}} \int_{-H}^{H}\left[\frac{2\left(z-z^{\prime}\right)^{2}-r^{2}}{R^{5}} \int_{\tau=0}^{\tau=t} i\left(z^{\prime}, \tau-\frac{R}{c}\right) d \tau\right. \\
+\frac{2\left(z-z^{\prime}\right)^{2}-r^{2}}{c R^{4}} i\left(z^{\prime}, t-\frac{R}{c}\right) \\
\left.-\frac{r^{2}}{c^{2} R^{3}} \frac{\partial i\left(z^{\prime}, t-R / \mathrm{c}\right)}{\partial t}\right] d z^{\prime}
\end{gathered}
$$




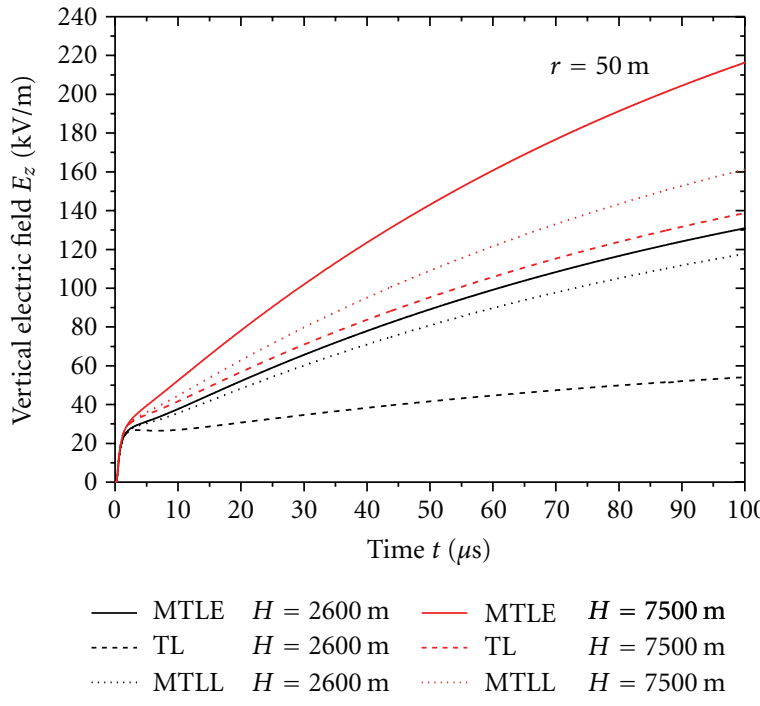

Figure 4: Vertical electric field at $50 \mathrm{~m}$ from the channel base for NCBC, three different models and two channel heights $(H=$ $2600 \mathrm{~m}$ and $7500 \mathrm{~m}$ ).

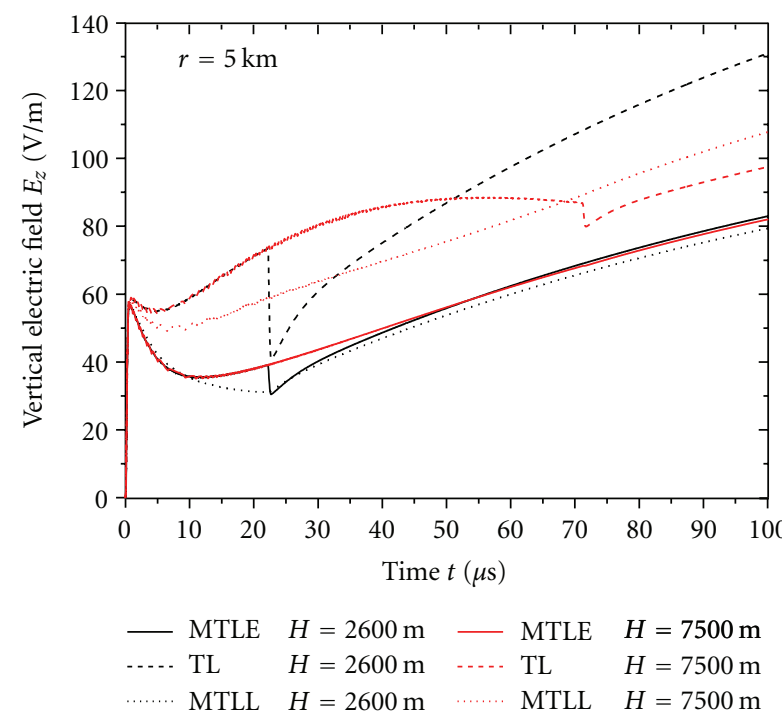

FIGURE 5: Vertical electric field at $5 \mathrm{~km}$ from the channel base for NCBC, three different models and two channel heights $(H=$ $2600 \mathrm{~m}$ and $7500 \mathrm{~m}$ ).

and radial electric field as

$$
\begin{aligned}
E_{r}=\frac{1}{4 \pi \varepsilon_{0}} \int_{-H}^{H}\left[\frac{3 r\left(z-z^{\prime}\right)}{R^{5}} \int_{\tau=0}^{\tau=t} i\left(z^{\prime}, \tau-\frac{R}{c}\right) d \tau\right. \\
+\frac{3 r\left(z-z^{\prime}\right)}{c R^{4}} i\left(z^{\prime}, t-\frac{R}{c}\right) \\
\left.+\frac{r\left(z-z^{\prime}\right)}{c^{2} R^{3}} \frac{\partial i\left(z^{\prime}, t-R / \mathrm{c}\right)}{\partial t}\right] d z^{\prime},
\end{aligned}
$$

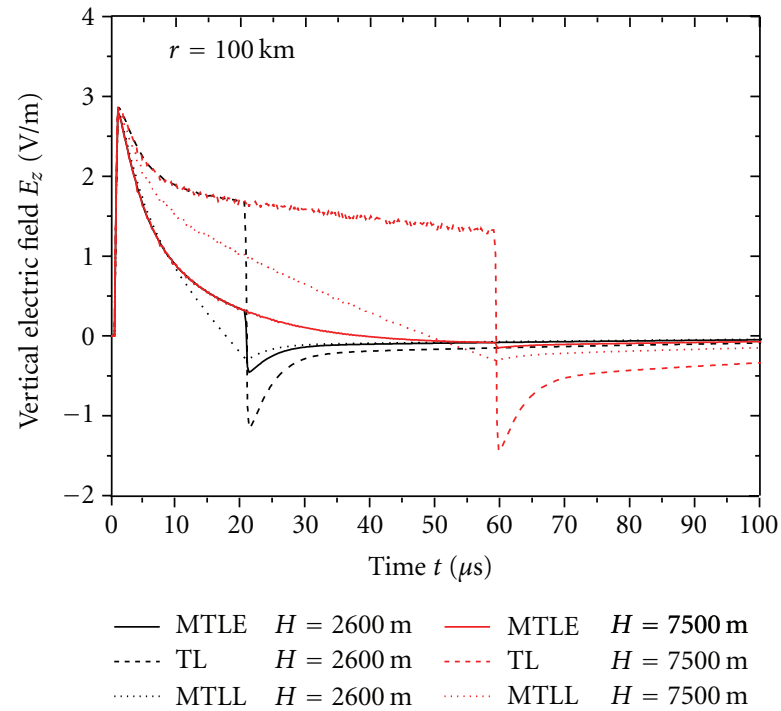

Figure 6: Vertical electric field at $100 \mathrm{~km}$ from the channel base for NCBC, three different models and two channel heights $(H=$ $2600 \mathrm{~m}$ and $7500 \mathrm{~m}$ ).

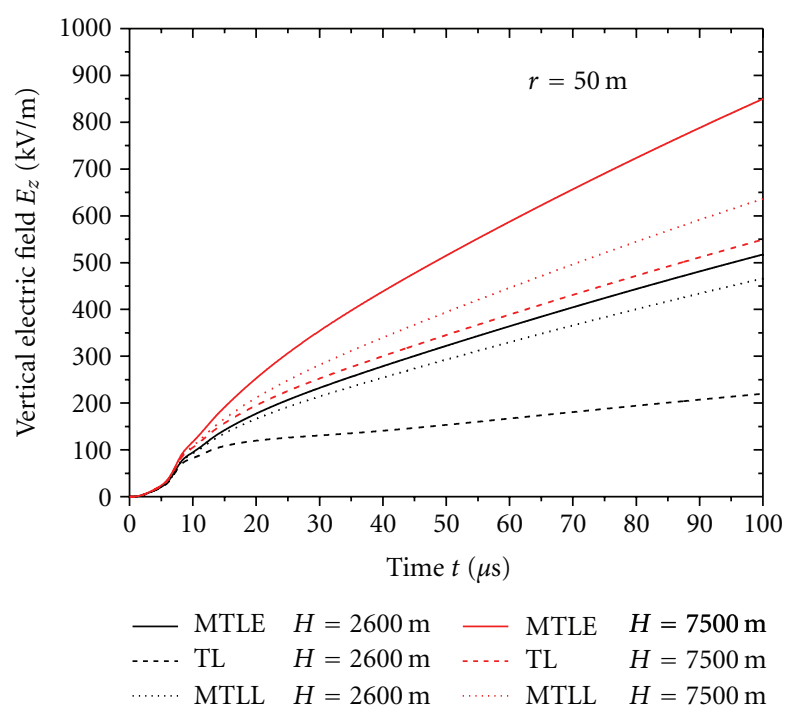

FIGURE 7: Vertical electric field at $50 \mathrm{~m}$ from the channel base for MSS_FST, three different models and two channel heights $(H=$ $2600 \mathrm{~m}$ and $7500 \mathrm{~m})$.

whereas azimuthal magnetic field is

$$
H_{\psi}=\frac{1}{4 \pi} \int_{-H}^{H}\left[\frac{r}{R^{3}} i\left(z^{\prime}, t-\frac{R}{c}\right)+\frac{r}{c R^{2}} \frac{\partial i\left(z^{\prime}, t-R / c\right)}{\partial t}\right] d z^{\prime},
$$

for $R=\sqrt{r^{2}+\left(z-z^{\prime}\right)^{2}}$ the distance from the current element of length $d z^{\prime}$, with the current $i\left(z^{\prime}, t\right)$ or its image in the plane mirror replacing the influence of the lower perfectly conducting half-space, to the field point $M(r, \psi, z)$. In (6), $c=\left(\varepsilon_{0} \mu_{0}\right)^{-1 / 2}$ is the speed of light, $\varepsilon_{0}$ is the permittivity and $\mu_{0}$ the permeability of the air. 


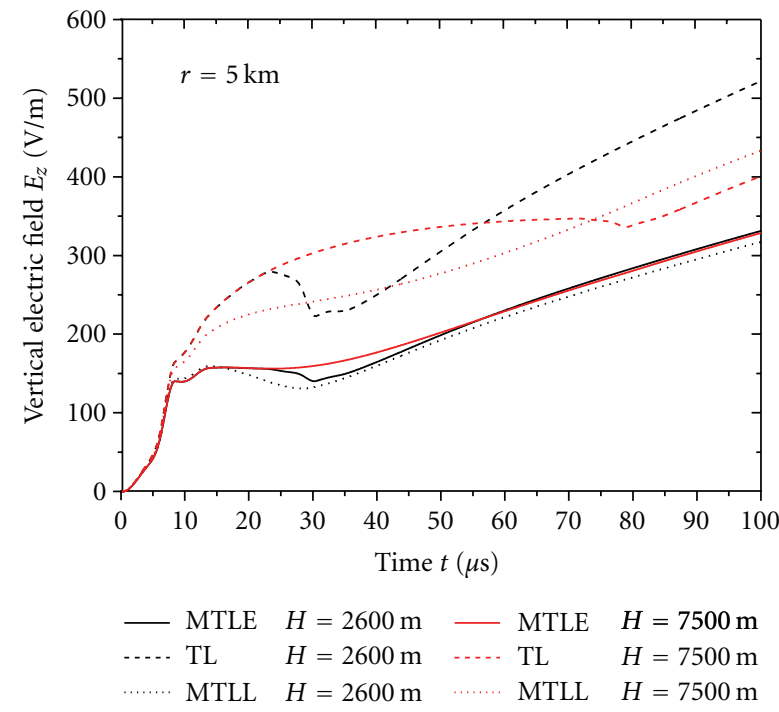

FIgURE 8: Vertical electric field at $5 \mathrm{~km}$ from the channel base for MSS_FST, three different models and two channel heights $(H=$ $2600 \mathrm{~m}$ and $7500 \mathrm{~m}$ ).

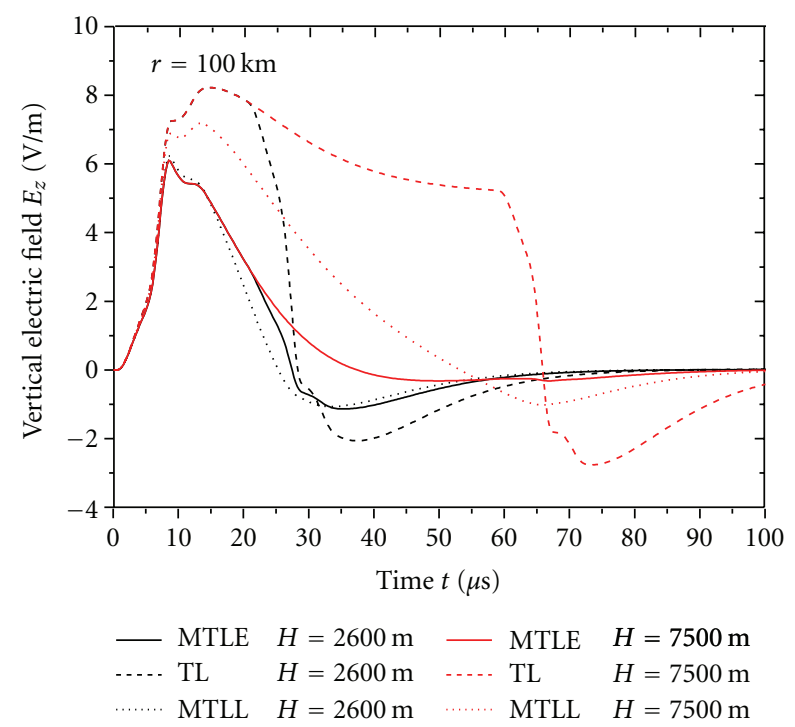

FIgURE 9: Vertical electric field at $100 \mathrm{~km}$ from the channel base for MSS_FST, three different models and two channel heights $(H=$ $2600 \mathrm{~m}$ and $7500 \mathrm{~m}$ ).

For the three "engineering" models (TL, MTLL, and MTLE), vertical electric field results are presented in Figures 4, 5, 6, 7, 8, and 9 for the two channel heights: $2600 \mathrm{~m}$ and $7500 \mathrm{~m}$.

For usually used waveshape from [9], approximated with one-peaked NCBC function [7], these results are presented in Figures 4-6 for the radial distances $50 \mathrm{~m}, 5 \mathrm{~km}$, and $100 \mathrm{~km}$ from the channel base.

For MSS_FST current from [3], approximated with [6], and the same three models, vertical electric field results are presented in Figures 7-9, for two different channel heights

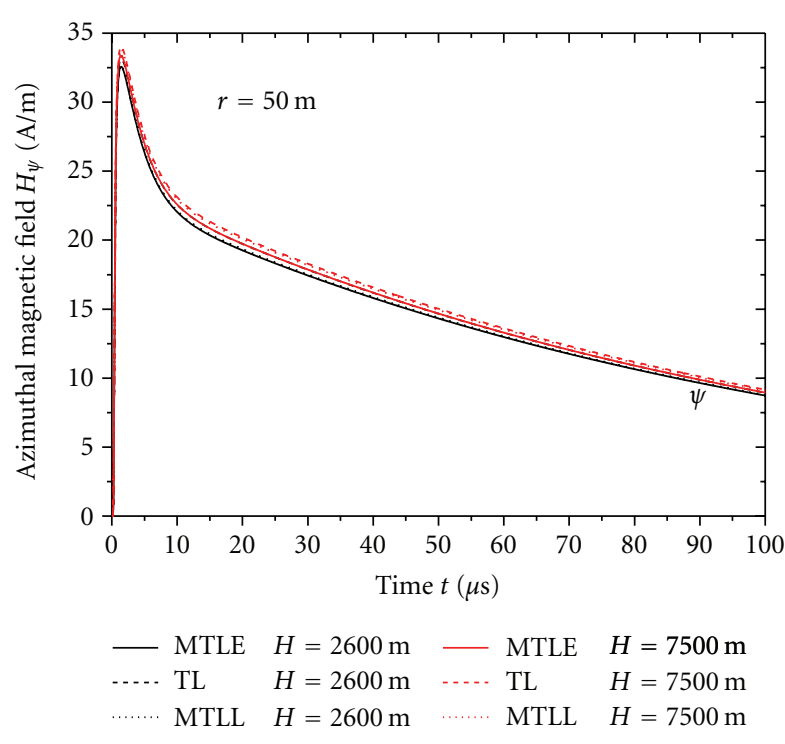

FIGURE 10: Azimuthal magnetic field at $50 \mathrm{~m}$ from the channel base for NCBC, three different models and two channel heights $(H=$ $2600 \mathrm{~m}$ and $7500 \mathrm{~m}$ ).

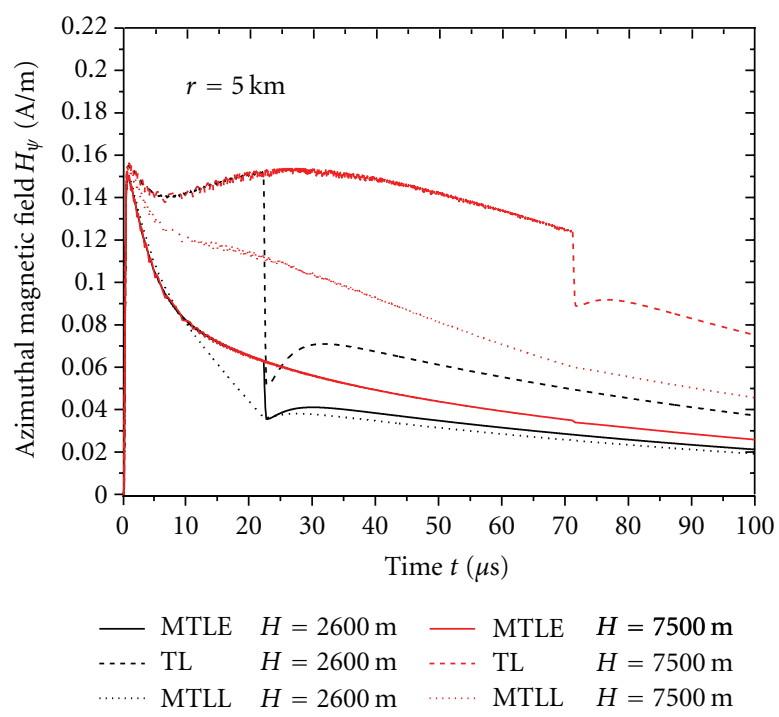

FIGURE 11: Azimuthal magnetic field at $5 \mathrm{~km}$ from the channel base for NCBC, three different models and two channel heights $(H=$ $2600 \mathrm{~m}$ and $7500 \mathrm{~m}$ ).

$(2600 \mathrm{~m}$ and $7500 \mathrm{~m}$ ), and for the distances $50 \mathrm{~m}, 5 \mathrm{~km}$, and $100 \mathrm{~km}$ from the channel base.

For MCS_FST current from [15], approximated with [6], lightning electric and magnetic field results are also obtained, but being similar to the waveshapes of MSS_FST, as can be concluded from Table 1, these are not included in this paper.

Azimuthal magnetic field results are presented for the one-peaked NCBC function in Figures 10, 11, and 12, and for the approximation of MSS_FST with the two-peaked current function in Figures 13, 14, and 15, for the distances $50 \mathrm{~m}$, 


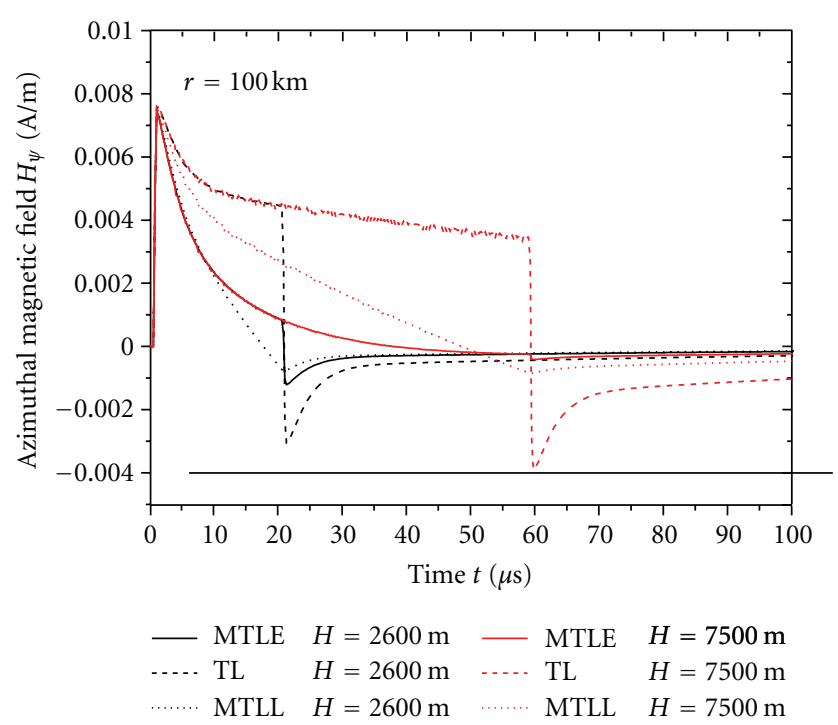

Figure 12: Azimuthal magnetic field at $100 \mathrm{~km}$ from the channel base for NCBC, three different models and two channel heights $(H=2600 \mathrm{~m}$ and $7500 \mathrm{~m})$.

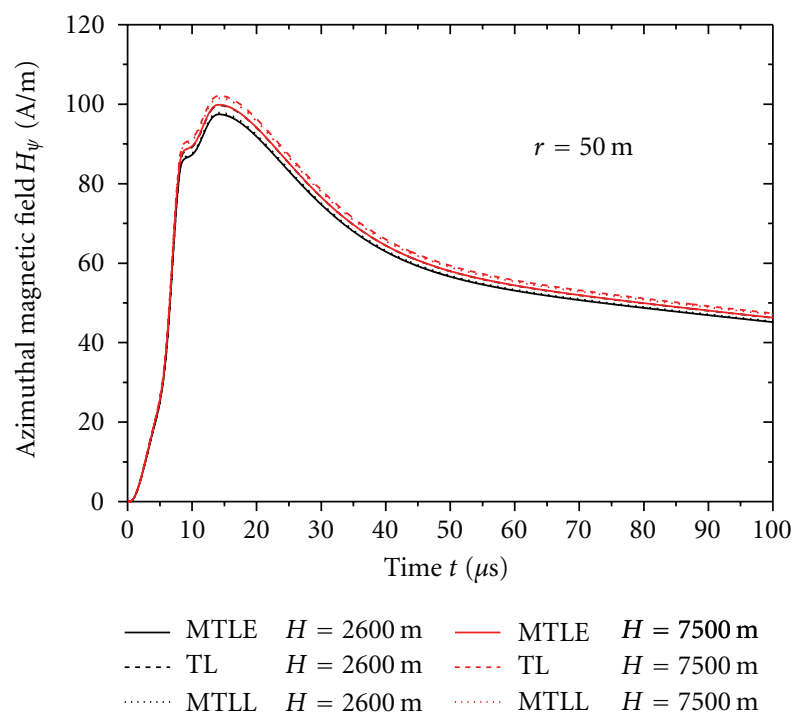

Figure 13: Azimuthal magnetic field at $50 \mathrm{~m}$ from the channel base for MSS_FST, three different models and two channel heights $(H=$ $2600 \mathrm{~m}$ and $7500 \mathrm{~m}$ ).

$5 \mathrm{~km}$, and $100 \mathrm{~km}$ from the channel base, and for the two different channel heights.

Some main features of lightning electromagnetic field waveshapes given in $[4,5,19]$ are: (1) a sharp initial peak in both electric and magnetic fields beyond a $\mathrm{km}$ or so, (2) a slow ramp following the initial peak for electric fields within a few tens of $\mathrm{km}$, (3) a hump following the initial peak in magnetic field within a few tens of $\mathrm{km}$, (4) a zero crossing within tens of microseconds after the initial peak in both electric and magnetic fields at 50-200 km, and (5)

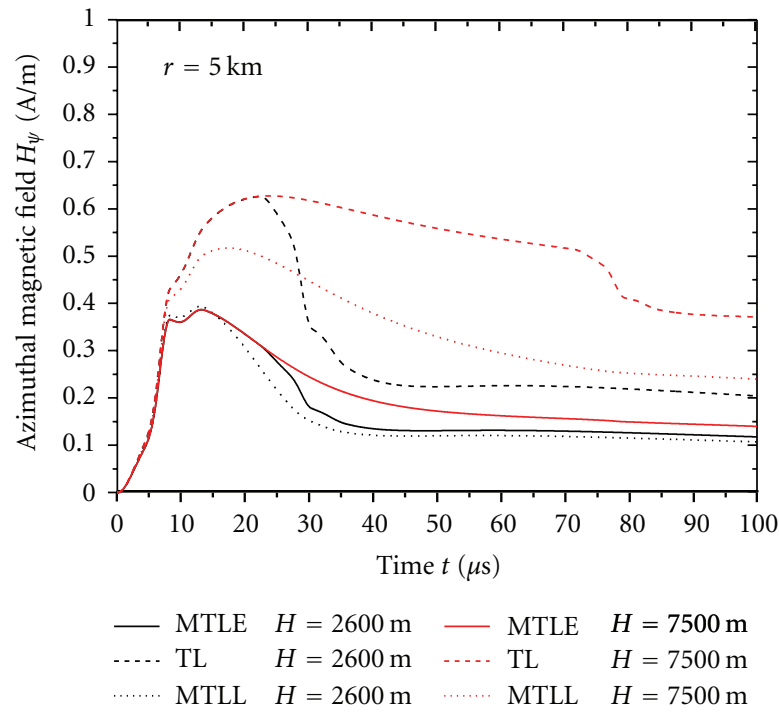

FIGURE 14: Azimuthal magnetic field at $5 \mathrm{~km}$ from the channel-base for MSS_FST, three different models and two channel heights $(H=$ $2600 \mathrm{~m}$ and $7500 \mathrm{~m}$ ).

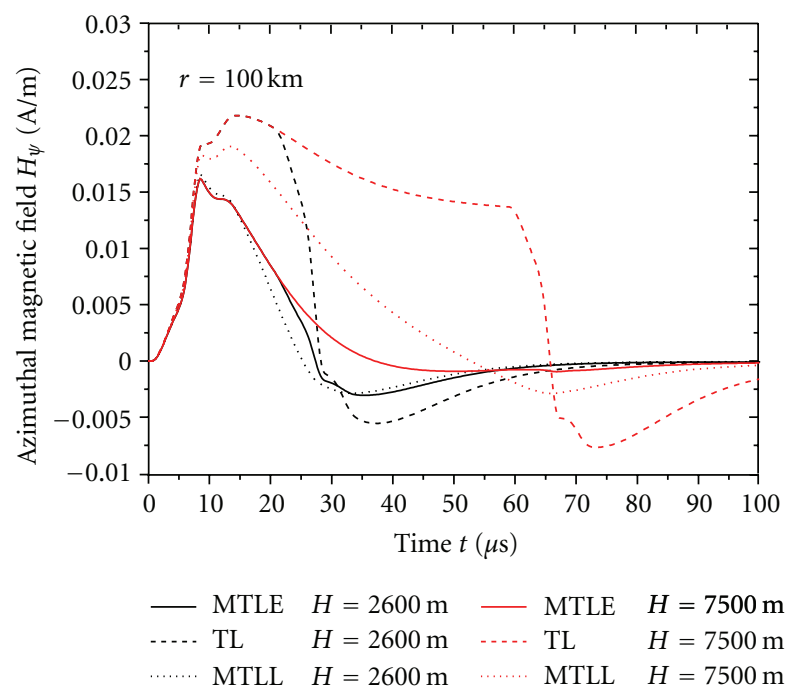

Figure 15: Azimuthal magnetic field at $100 \mathrm{~km}$ from the channelbase for MSS_FST, three different models and two channel heights $(H=2600 \mathrm{~m}$ and $7500 \mathrm{~m})$.

a characteristic flattening of vertical electric field at tens to hundreds of meters.

It can be concluded from these results that magnetic field at a few tens of meters follows the channel-base current waveshape. The feature (1) is valid for all the models, and (2) a slow ramp is obtained with TL model after tens of microseconds, so as with other models. A hump mentioned as the feature (3) is obtained at $5 \mathrm{~km}$ with TL and MTLE model, whereas for NCBC just with TL model. A zero crossing mentioned as (4) is obtained for far fields with TL 
model also, so as with others. The characteristic flattening (5) is obtained with TL model calculated for smaller channel heights. Some of these features are not obtained for all the models if a one-peaked channel-base current is used.

\section{Conclusion}

New functions for approximating one- and two-peaked lightning channel-base current waveshapes are used in this paper. Parameters of these functions are calculated for the measured channel-base currents, so as for the current waveshape often used in the literature. Similarly derived functions can be used to approximate even more peaks in the current waveshapes which are characteristic for the measured negative first-stroke currents.

The three different "engineering" models (transmission line model, transmission line model with linear decay, and transmission line model with exponential decay with height) are used for calculating lightning electromagnetic field. These results enable analysis of the models efficiency and validity. In this analysis transmission line model with linear decay proved to have some advantages over other two models if a double-peaked channel-base current is used.

The new one- and two-peaked channel-base current functions also have analytically obtained derivatives and integrals, so as Fourier transforms which are very useful for electromagnetic modeling and for application in frequency domain $[20,21]$. The next step would be including more peaks in the rising part of the channel-base current to comply better with measurements results of channel-base currents and lightning electromagnetic field components.

\section{Acknowledgment}

This paper is supported by the Project Grant III44004 (20112014) financed by the Ministry of Education and Science, Republic of Serbia.

\section{References}

[1] K. Berger, R. B. Anderson, and H. Kroninger, "Parameters of lightning flashes," Electra, vol. 80, pp. 23-37, 1975.

[2] Y. T. Lin, M. A. Uman, J. A. Tiller et al., "Characterization of lightning return stroke electric and magnetic fields from simultaneous two-station measurements," Journal of Geophysical Research, vol. 84, no. 10, pp. 6307-6314, 1979.

[3] R. B. Anderson and A. J. Eriksson, "Lightning parameters for engineering application," Electra, vol. 69, pp. 65-102, 1980.

[4] V. A. Rakov and M. A. Uman, "Review and evaluation of lightning return stroke models including some aspects of their application," IEEE Transactions on Electromagnetic Compatibility, vol. 40, no. 4, pp. 403-426, 1998.

[5] R. Thottappillil and V. A. Rakov, "Distribution of charge along the lightning channel: relation to remote electric and magnetic fields and to return-stroke models," Journal of Geophysical Research D, vol. 102, no. 6, pp. 6987-7006, 1997.

[6] V. Javor, "Approximation of a double-peaked lightning channel-base current," COMPEL, vol. 31, no. 3, pp. 10071017, 2012.
[7] V. Javor and P. D. Rancic, "A channel-base current function for lightning return-stroke modeling," IEEE Transactions on Electromagnetic Compatibility, vol. 53, no. 1, pp. 245-249, 2011.

[8] V. Javor, "Approximating decaying part of the lightning return stroke channel-base current," in Proceedings of the 3rd International Symposium on Lightning Physics and Effects, p. 26, Vienna, Austria, 2008.

[9] C. A. Nucci, G. Diendorfer, M. A. Uman, F. Rachidi, M. Ianoz, and C. Mazzetti, "Lightning return stroke current models with specified channel-base current: a review and comparison," Journal of Geophysical Research, vol. 95, no. 12, pp. 2039520408, 1990.

[10] F. Heidler, "Travelling current source model for LEMP calculation," in Proceedings of the 6th International Zurich Symposium on EMC, pp. 157-162, Zurich, Switzerland, 1985.

[11] F. Heidler and J. Cvetić, "A class of analytical functions to study the lightning effects associated with the current front," European Transactions on Electrical Power, vol. 12, no. 2, pp. 141-150, 2002.

[12] F. Heidler and Ch. Hopf, "Initial and subsidiary peak of the lightning electromagnetic fields considering channel-base current and reflections at the return stroke channel," in Proceedings of the 9th International Symposium on High Voltage Eng. ISH, Graz, Austria, 1995.

[13] A. De Conti and S. Visacro, "Analytical representation of single- and double-peaked lightning current waveforms," IEEE Transactions on Electromagnetic Compatibility, vol. 49, no. 2, pp. 448-451, 2007.

[14] F. H. Silveira, A. De Conti, and S. Visacro, "Lightning overvoltage due to first strokes considering a realistic current representation," IEEE Transactions on Electromagnetic Compatibility, vol. 52, no. 4, Article ID 5437248, pp. 929-935, 2010.

[15] S. Visacro, A. Soares, M. A. O. Schroeder, L. C. L. Cherchiglia, and V. J. de Sousa, "Statistical analysis of lightning current parameters: measurements at Morro do Cachimbo station," Journal of Geophysical Research D, vol. 109, no. 1, Article ID D01105, 11 pages, 2004.

[16] V. Javor, "New functions for representing IEC 62305 standard and other typical lightning stroke currents," Journal of Lightning Research. In press.

[17] IEC 62305 standard, "Protection against lightning-Part I: General principles," 2006.

[18] R. Moini, B. Kordi, G. Z. Rafi, and V. A. Rakov, "A new lightning return stroke model based on antenna theory," Journal of Geophysical Research D, vol. 105, no. 24, pp. 2969329702, 2000.

[19] C. Gomes and V. Cooray, "Concepts of lightning return stroke models," IEEE Transactions on Electromagnetic Compatibility, vol. 42, no. 1, pp. 82-96, 2000.

[20] V. Javor and P. D. Rančić, "Frequency domain analysis of the lightning protection using four vertical lightning protection rods," Serbian Journal of Electrical Engineering, vol. 5, no. 1, pp. 109-120, 2008.

[21] V. Javor and P. D. Rančić, "Electromagnetic field in the vicinity of lightning protection rods at a lossy ground," IEEE Transactions on Electromagnetic Compatibility, vol. 51, no. 2, pp. 320-330, 2009. 

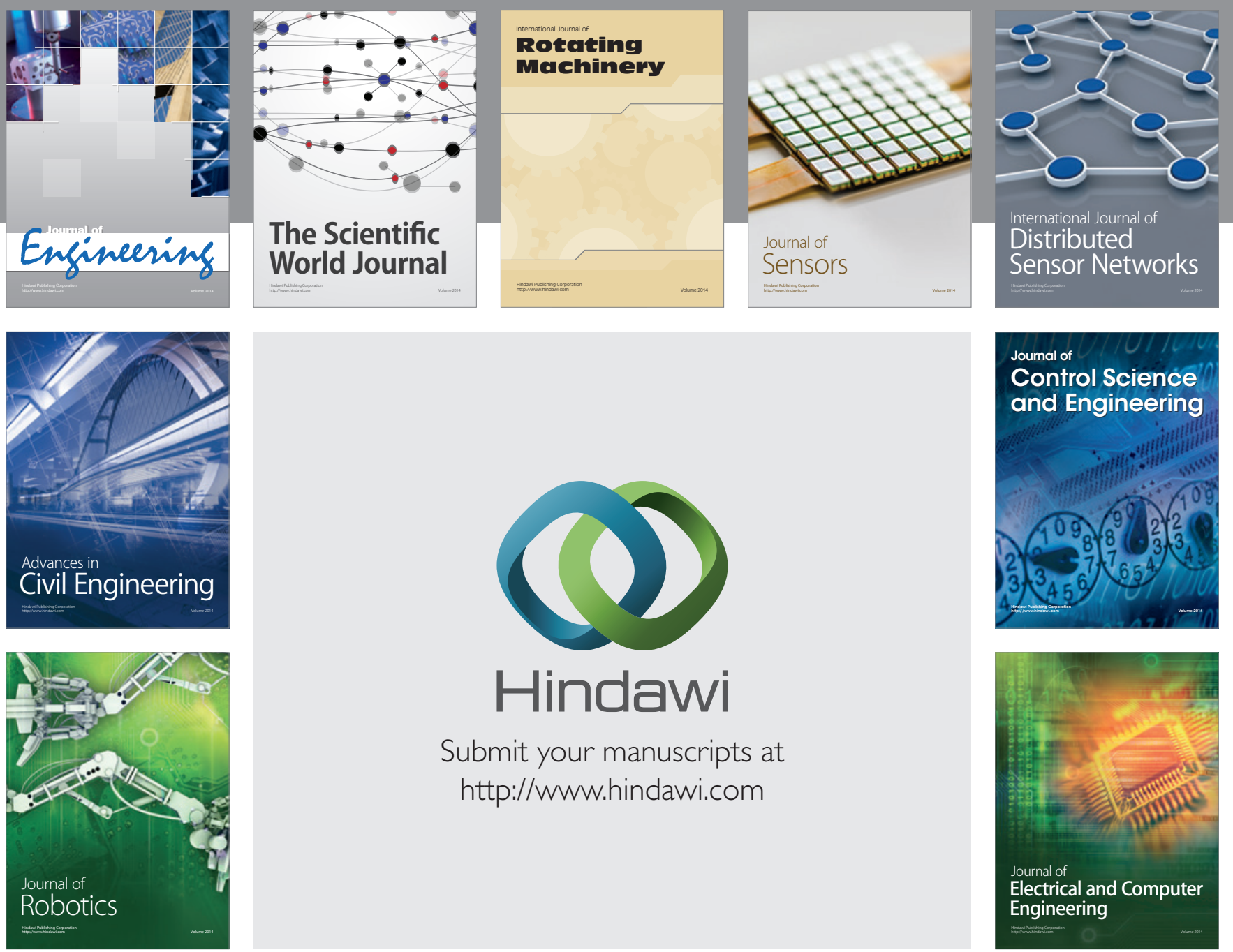

Submit your manuscripts at

http://www.hindawi.com
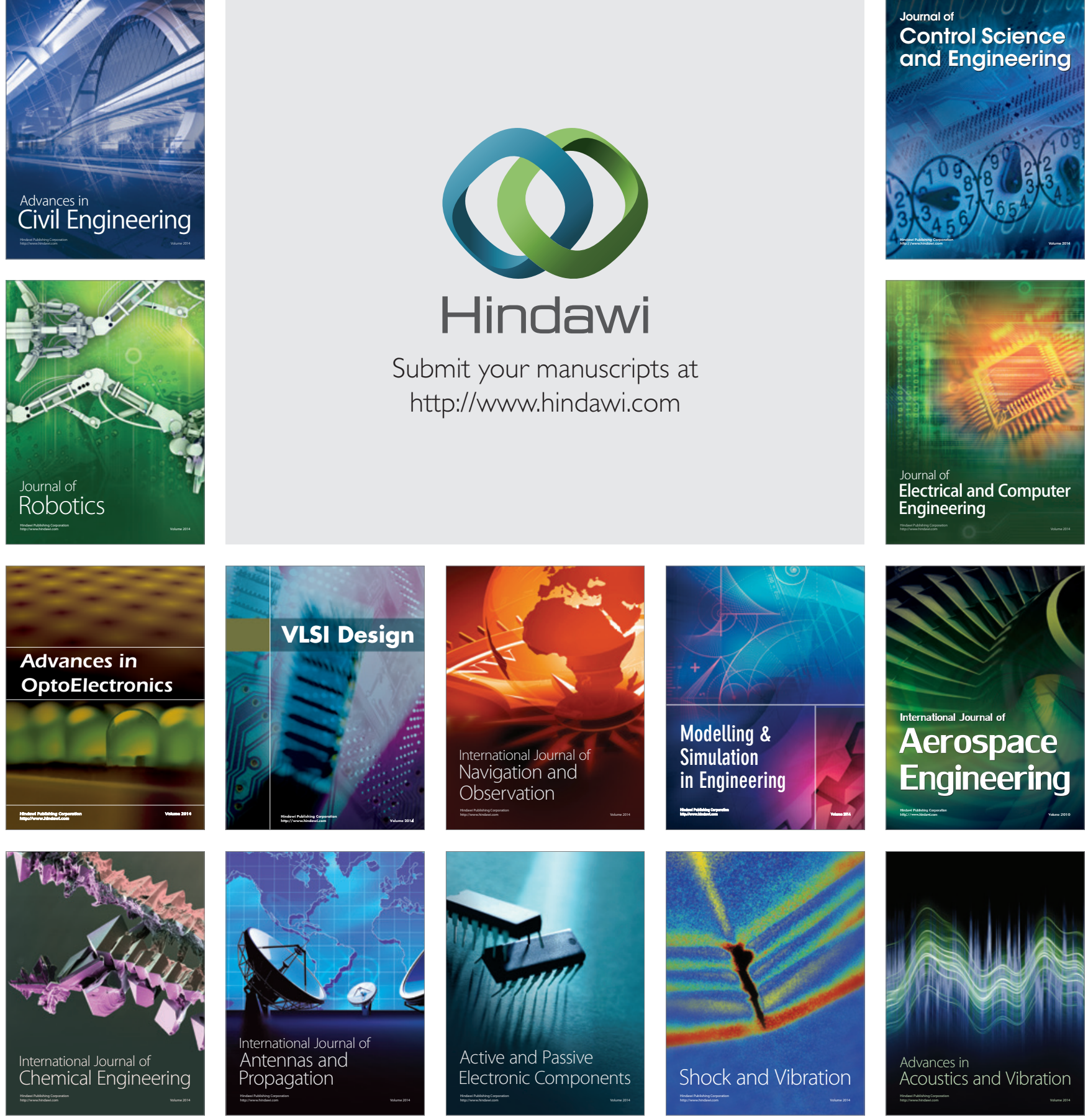